\title{
Experimental Study of Onset of Nucleate Boiling in Vertical Rectangular Channels with Different Flow Path Heights
}

\author{
Ning Cheng $\mathbb{D},{ }^{1,2}$ Shuwen Yu $\left(\mathbb{D},,^{1}\right.$ Jun Xiao $\mathbb{D}^{3},{ }^{3}$ and Chang-Hong Peng $\mathbb{D}^{1}$ \\ ${ }^{1}$ School of Nuclear Science and Technology, University of Science and Technology of China, Hefei 230026, China \\ ${ }^{2}$ China Ship Development and Design Center, Wuhan 430060, China \\ ${ }^{3}$ Nuclear and Radiation Safety Center, Ministry of Ecology and Environment (MEE) of the People's Republic of China, \\ Beijing 100000, China \\ Correspondence should be addressed to Jun Xiao; xiaojun70@163.com
}

Received 21 October 2021; Revised 20 December 2021; Accepted 27 December 2021; Published 30 January 2022

Academic Editor: Iztok Tiselj

Copyright (c) 2022 Ning Cheng et al. This is an open access article distributed under the Creative Commons Attribution License, which permits unrestricted use, distribution, and reproduction in any medium, provided the original work is properly cited.

\begin{abstract}
A study on ONB (onset of nucleate boiling) in two vertical rectangular channels are experimentally conducted in a range of mass flux varying from 100 to $300 \mathrm{~kg} /\left(\mathrm{m}^{2} \cdot \mathrm{s}\right)$, inlet water temperature from 70 to $100^{\circ} \mathrm{C}$, heat flux from 10 to $70 \mathrm{~kW} / \mathrm{m}^{2}$, and $l o c a l$ pressure of $0.145 \mathrm{MPa}$. The cross-section sizes are $1.8 \mathrm{~mm} * 60 \mathrm{~mm}$ and $2.8 \mathrm{~mm} * 60 \mathrm{~mm}$, respectively. Three boiling incipience judgment methods have been used to locate ONB sites and found that $\Delta T_{\mathrm{ONB}}$ (the wall superheat at ONB site) increases with the decrease of inlet temperature and increases as mass flux increases. The results also indicate that although the bubble size and behaviors in the narrow channel are different from that in the nonnarrow channel at the ONB site, the heat transfer has not been influenced evidently. In addition, $\Delta T_{\mathrm{ONB}}$ in both channels can be predicted by the correlation proposed by Thom within the error range of $\pm 30 \%$.
\end{abstract}

\section{Introduction}

Subcooled flow boiling is the most common form of flow boiling in engineering fields. The wall temperature is over liquid saturation temperature at local pressure, and bubbles generate on the heated surface, but the average fluid bulk temperature is kept below saturation temperature. The ONB marks the transformation of one-phase flow into the twophase flow. Although bubbles can improve heat transfer efficiency, they also lead to unfavourable hydraulic events such as onset of flow instability (OFI) and critical heat flux (CHF).

Many studies have been done to research the ONB since the last century. Hsu [1] conducted the earliest research and proposed equation (1) based on a model where bubbles occur in a small gas-containing cavity on a heated surface. The superheat of the liquid calculated by this heterogeneous nucleation model is much lower than that calculated by the homogeneous nucleation theory and is much closer to the actual situation. Sato and Matsumura [2], Bergles and Rohsenow [3], and Kandlikar [4] developed Hsu's model and proposed improved models. Jens and Lottes [5], Thom et al. [6], and Al Yahia and Jo [7] conducted a fully developed nucleation heat transfer experiment with water as a working fluid and proposed ONB models based on experimental data. Recently, Song et al. [8] and Hong et al. [9] summarized empirical correlations based on their experimental. All the ONB correlations are given in Table 1. Although lots of research works have been done, experimental data in vertical rectangular runners are still lacking, and the effect of the cross-section aspect ratio of the rectangular runner remains unclear. In the present work, the boiling incipience in two rectangular channels whose height is $1.8 \mathrm{~mm}$ and $2.8 \mathrm{~mm}$ has been investigated, and $\Delta T_{\mathrm{ONB}}$ got by experiment has been compared with existing correlations.

\section{Experimental Facility and Procedure}

Figure 1 shows the experimental circuit. The mass flux is modified and monitored by the butterfly valve and flow meter. The pressure of the system is controlled by a 
TABLE 1: ONB models in the literature.

\begin{tabular}{|c|c|c|}
\hline Author(s) & Correlations & Range of applicability \\
\hline Hsu [1] & $\Delta T_{\mathrm{ONB}}=\sqrt{12.8 \sigma T_{\mathrm{sat}} q^{\prime \prime} / k_{l} h_{l v} \rho_{v}}$ & - \\
\hline Sato and Matsumura [2] & $\Delta T_{\mathrm{ONB}}=\sqrt{8 \sigma T_{\mathrm{sat}} q^{\prime \prime} / k_{l} h_{l v} \rho_{v}}$ & - \\
\hline Bergles and Rohsenow [3] & $\Delta T_{\mathrm{ONB}}=5 / 9\left(q^{\prime \prime} / 1082 P^{1.156}\right)^{p^{0.0234} / 2.16}$ & $0.1 \mathrm{MPa}<p<13.8 \mathrm{MPa}$ \\
\hline Kandlikar [4] & $\Delta T_{\mathrm{ONB}}=\sqrt{8.8 \sigma T_{\mathrm{sat}} q^{\prime \prime} / k_{l} h_{l v} \rho_{v}}$ & - \\
\hline Jens and Lottes [5] & $\Delta T_{\mathrm{ONB}}=25\left(q^{\prime \prime} / 10^{6}\right)^{0.25} e^{(-p / 6.2)}$ & $3.5 \mathrm{MPa}<p<14 \mathrm{MPa}$ \\
\hline Thom et al. [6] & $\Delta T_{\mathrm{ONB}}=22.65\left(q^{\prime \prime} / 10^{6}\right)^{0.5} e^{(-p / 8.7)}$ & $\begin{aligned} 6.8 \mathrm{MPa} & <p<13.6 \mathrm{MPa} \\
290 \mathrm{~kW} / \mathrm{m}^{2} & \leq q<1570 \mathrm{~kW} / \mathrm{m}^{2} \\
0.1 \mathrm{MPa} & <p<0.13 \mathrm{MPa}\end{aligned}$ \\
\hline Al Yahia and Jo [7] & $\Delta T_{\mathrm{ONB}}=7.36\left(q^{\prime \prime} / 10^{3}\right)^{0.5} e^{(-p / 9.5)}$ & $\begin{array}{l}0.015 \mathrm{~kg} / \mathrm{s}<\dot{m}<0.0130 \mathrm{~kg} / \mathrm{s} \\
50 \mathrm{~kW} / \mathrm{m}^{2} \leq q<800 \mathrm{~kW} / \mathrm{m}^{2}\end{array}$ \\
\hline Song et al. [8] & $\begin{array}{c}\Delta T_{\mathrm{ONB}}=e^{7.603} * \mathrm{Bo}^{2.221} * \mathrm{Re}^{0.909} * T_{\text {sub }}^{-1.275} \\
\text { Bo }=q^{\prime \prime} / \mathrm{Gh}_{l v} \\
\Delta T_{\mathrm{ONB}}=0.05 \mathrm{Re}^{0.156}\left(\rho_{v} / \rho_{l}\right)^{-0.413} \mathrm{Bo}^{1.321}\end{array}$ & $\begin{array}{c}p=0.1 \mathrm{MPa} \\
800 \mathrm{~kg} /\left(\mathrm{m}^{2} \cdot \mathrm{s}\right)<G<1200 \mathrm{~kg} /\left(\mathrm{m}^{2} \cdot \mathrm{s}\right) \\
0.18 \mathrm{MPa}<p<0.195 \mathrm{MPa}\end{array}$ \\
\hline Hong et al. [9] & Bo $=q^{\prime \prime} / \mathrm{Gh}_{l v}$ & $\begin{array}{c}298 \mathrm{~kg} /\left(\mathrm{m}^{2} \cdot \mathrm{s}\right)<G<840 \mathrm{~kg} /\left(\mathrm{m}^{2} \cdot \mathrm{s}\right) \\
33 \mathrm{~kW} / \mathrm{m}^{2} \leq q<184 \mathrm{~kW} / \mathrm{m}^{2}\end{array}$ \\
\hline
\end{tabular}
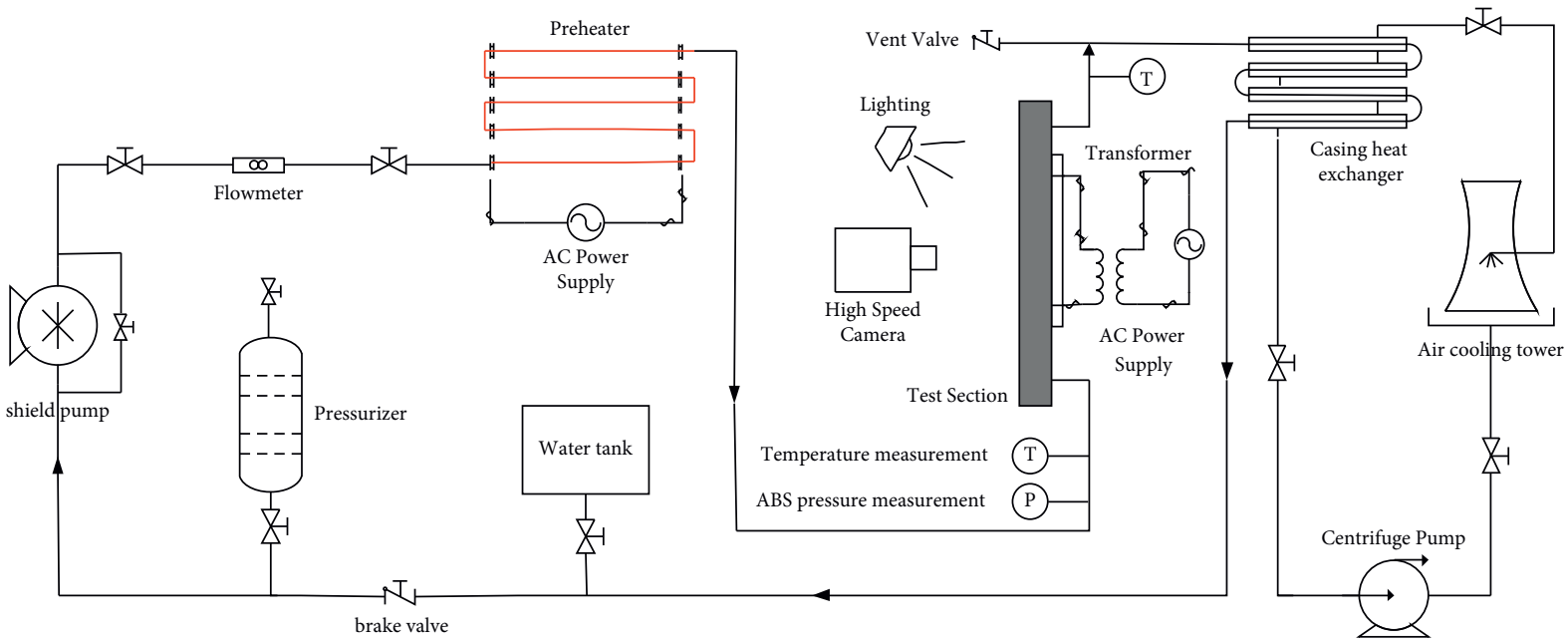

FIgURE 1: Schematic diagram of the experimental loop.

pressurizer and vent valve, and the working fluid water is heated to specified temperature in the preheater section and heated to boiling in the test section. The excess heat is removed from the primary circuit to the secondary circuit by a heat exchanger. Then, it is dissipated to the surrounding environment by an air-cooling tower.

Two structurally similar test sections have been adopted. Figure 2(a) shows the test section's diagram, and it comprises a heating plate, stainless steel plate, high-temperature resistance glass, and pressing plate. Figure 2 (b) shows the details of the stainless steel plate. $36 \mathrm{~cm}$ deep holes were on the side of the steel plate as two rows to insert thermocouples. So, the heat fluxa $q^{\prime \prime}$ can be calculated by

$$
q^{\prime \prime}=\lambda \frac{T_{2}-T_{1}}{L}
$$

where $\lambda$ is the thermal conductivity of stainless steel $(16.2 \mathrm{~W} /$ $(\mathrm{m} \cdot \mathrm{K})), T_{2}$ is the temperature measured by the row of holes near the heating plate, $T_{1}$ is the temperature of the holes close to the flow channel, and $L$ is the $10 \mathrm{~mm}$ length between the two rows of holes. The size of test sections and experimental range are given in Table 2 .

Before the experiment, a boiling water temperature test at one standard atmosphere should be done in a boiling pool to calibrate the temperature collector and determine the measurement error of K-type thermocouples. Figure 3 shows the temperature measurement results; the black line represents the mercury thermometer's temperature. The black points and red points stand for the temperature measured by thermocouples and thermal resistors at the same condition. It can be seen that all the measurement errors are within $\pm 0.5^{\circ} \mathrm{C}$, which agree with the data provided by the manufacturer. The measurement accuracy of all kinds of signals is given in Table 3, and the data collector is Keithley 2750.

Before the experiment, the deionized water in the loop would be heated to boiling for half an hour to remove the gas dissolved in the water. Next, the degassed water flowed at a constant mass flow rate and was heated to a specified temperature by the preheater. Then, the fluid was heated to boiling in the test section with the heat flux controlled by the 


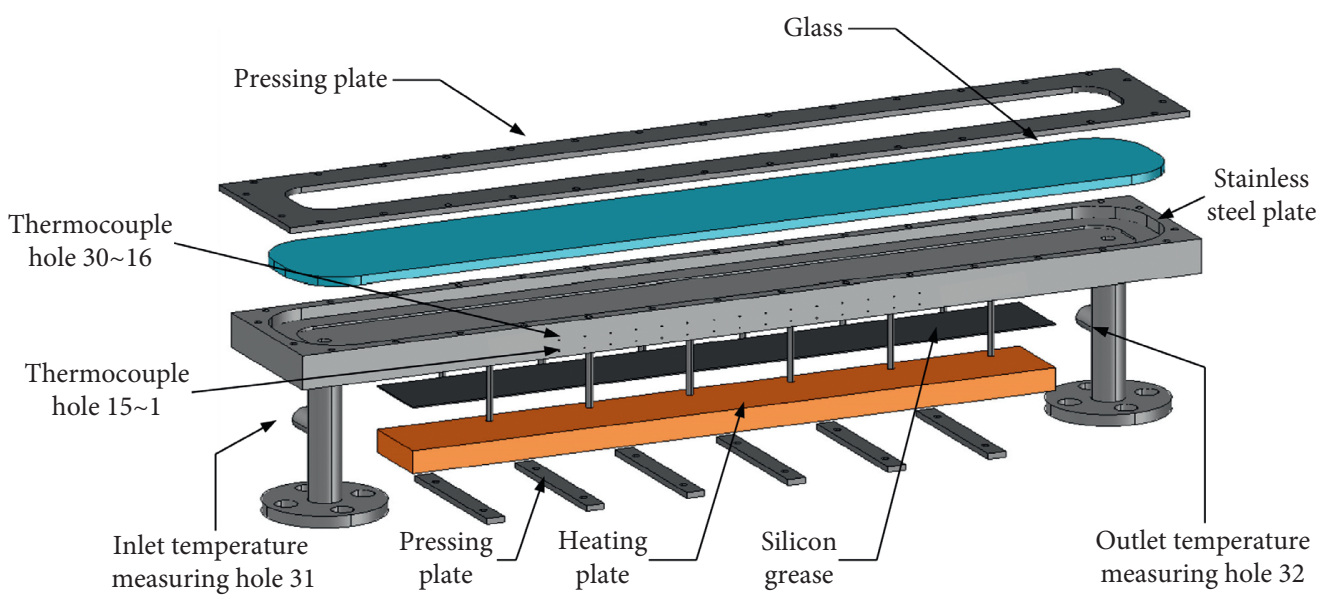

(a)

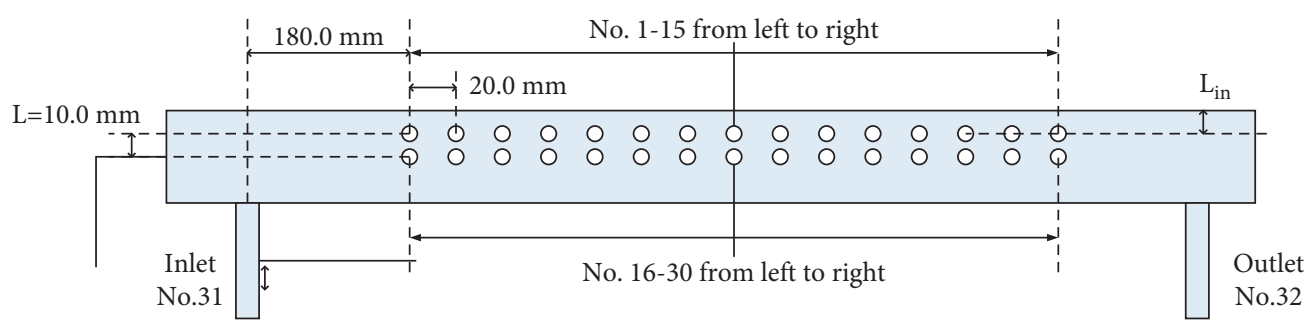

(b)

FIgURE 2: Schematic of test sections.

TABLE 2: Parameters and experimental range of two test sections.

Size (mm)

Hydraulic diameter, $D_{\text {hy }}(\mathrm{mm})$

Pressure, $p(\mathrm{MPa})$

Mass flux, $G\left(\mathrm{~kg} /\left(\mathrm{m}^{2} \cdot \mathrm{s}\right)\right)$

Inlet temperature, $T_{\text {in }}\left({ }^{\circ} \mathrm{C}\right)$

Heat flux, $q\left(\mathrm{~kW} / \mathrm{m}^{2}\right)$

Channel a
$1.8 \times 60.0 \times 610.0$
3.50
0.145
100,200 , and 300
$70-100$
$10-70$

$10-70$
Channel b
$2.8 \times 60.0 \times 610.0$
5.35
0.145

100,200 , and 300

$70-100$

$10-70$

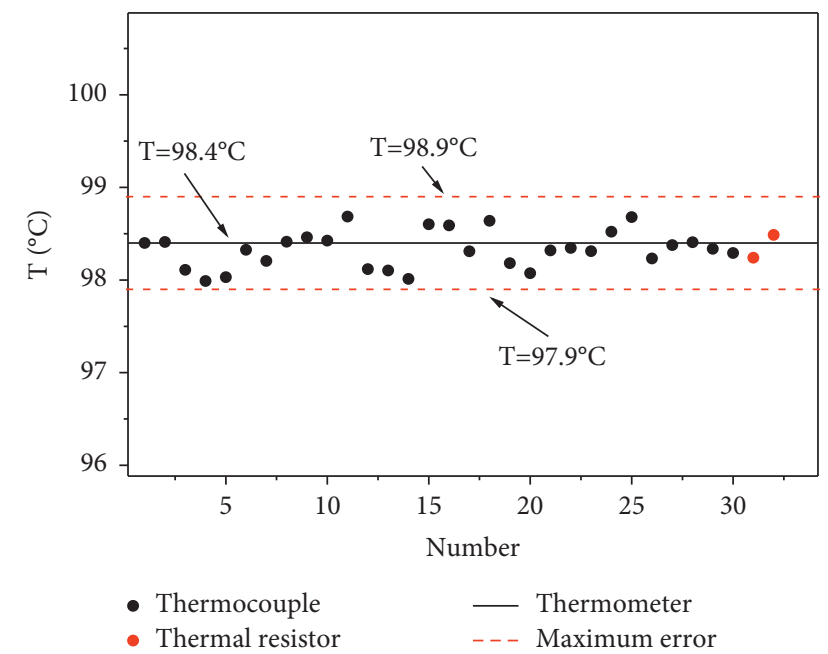

Figure 3: Thermocouple calibration. transformer increased step by step, the inlet fluid temperature and mass flux remained kept. The bubble behaviors were recorded by a high-speed camera (Phantom V1212) in the test section. During the experiment, the pressure in the middle of the experimental section was maintained at $0.145 \mathrm{MPa}$.

\section{Results and Discussion}

3.1. Identification of Minichannel. Many methods for identifying minichannels have been proposed in the literature. According to the criteria proposed by Kandlikar [10], the pipes can be divided into three types: conventional channels: $D_{\text {hy }}>3 \mathrm{~mm}$, minichannels: $3 \mathrm{~mm}>D_{\text {hy }}>0.2 \mathrm{~mm}$, and microchannels: $0.2 \mathrm{~mm}>D_{\text {hy }}>0.01 \mathrm{~mm}$.

Another definition is given by Cheng et al. [11] based on analysis considering the magnitudes of gravity and surface tension effects: macrochannel: $\mathrm{Bd}>3.0$; minichannel: $3.0>$ Bd > 0.5; microchannel: $0.5>$ Bd. 
TABLE 3: Measurement accuracy.

\begin{tabular}{|c|c|c|c|}
\hline Temperature & $\begin{array}{l}\text { Measurement signals } \\
\text { Inlet and outlet fluid temperature } \\
\text { Wall temperature }\end{array}$ & $\begin{array}{l}\text { Measurement instruments } \\
\Phi 6 \mathrm{~mm} \text { Pt100 thermal resistors } \\
\Phi 1 \mathrm{~mm} \text { K-type thermocouples }\end{array}$ & $\begin{array}{l}\text { Measurement accuracy } \\
\qquad 0.5^{\circ} \mathrm{C} \\
\pm 0.5^{\circ} \mathrm{C}\end{array}$ \\
\hline Pressure & Absolute pressure & 3151SA pressure gauge & $0.15 \%$ \\
\hline Flow mass & Mass flow rate & PEL-L024 turbine flow meter & $1.25 \%$ \\
\hline Voltage & Voltage of test section & D65-V voltmeter & $0.2 \%$ \\
\hline Current & Current of test section & D65-A ammeter & $0.2 \%$ \\
\hline \multirow{2}{*}{ Length } & Size of test section & Meter stick & $1 \mathrm{~mm}$ \\
\hline & Size of cross-section & Vernier calliper & $0.01 \mathrm{~mm}$ \\
\hline
\end{tabular}

$$
\mathrm{Bd}=\frac{g\left(\rho_{l}-\rho_{g}\right) D_{\mathrm{hy}}^{2}}{\sigma},
$$

where $\mathrm{Bd}$ is the bond number, and $g$ is the acceleration due to gravity. Kew and Cornwell [12] believed that when the value of confinement number Co is more than 0.5, the confinement effects will be significant and Co is defined as

$$
\mathrm{Co}=\sqrt{\frac{\sigma}{g\left(\rho_{l}-\rho_{g}\right) D_{\mathrm{hy}}^{2}}} .
$$

It can be found that when it comes to rectangular channels with a high aspect ratio, the aspect ratio for channel $a$ is 33.3 and for channel $b$ is 21.4. In Table 4, there will be some differences between the judgment results obtained by three methods. Channel $b$ is defined as a macro/conventional channel with no apparent channel confinement effects by each criterion. According to Cheng and $\mathrm{Wu}$, channel a is defined as a conventional channel according to Kandlikar or minichannel despite a tiny channel gap, but a microchannel is with significant channel confinement effects by Kew and Cornwell.

According to Yin and Jia [13, 14], an essential feature of channel confinement effects is that the bubble shape began to deform periodically after OCC (onset of channel confinement). The feature can be represented by the fluctuated variation features of bubble shape parameters such as root contact angle and bubble aspect ratio. In this experiment, since there are few bubbles near the ONB point, a typical bubble's shape and behaviors can be easily observed. They have been obviously affected by the channel size, as shown in Figure 4. The bubble equivalent diameter changed periodically, but this phenomenon cannot be observed in channel $b$ under the same flow and heating conditions. On the one hand, the superheated layer in channel a is not as high as in channel b. On the other hand, higher flow velocity in channel a reduces the thickness of the superheated layer. Evaporation and condensation have reached a dynamic equilibrium; then, the bubble touching the subcooled liquid periodically increases and shrinks. Therefore, the judgment criterion proposed by Kew and Cornwell may be more suitable for high aspect ratio rectangular channels. It can be observed that bubbles in channel a are more challenging to leave away from the nucleation point and slide along the wall. In Figure 5, it can be seen that the nucleation site is more in channel a than in channel $b$ at the same area.
3.2. Estimation of ONB Sites. There are many methods to estimate the location of ONB sites in previous literature. Hapke et al. [15] judged the ONB site by measuring local heat transfer coefficient and axial wall temperature. Chen et al. [16] used a transient flux measurement technique and a high-speed camera to study ONB. Wang et al. [17] measured pressure drop and heat transfer coefficient at a fixed point to identify the ONB site. Al Yahia and Jo [7] changed heat flux step by step and recorded wall superheat at a fixed point to determine the ONB point.

Axial wall temperature distribution, photos at a fixed point, and wall superheat at a fixed point are used to identify the ONB site. The mass flux keeps at $100 \mathrm{~kg} /\left(\mathrm{m}^{2} \cdot \mathrm{s}\right)$, and $T_{\text {in }}$ remains at $70^{\circ} \mathrm{C}$ in channel $\mathrm{b}$ is presented as an example case. Figure 6 shows the axial wall temperature $T_{\text {wall }}$ when heat power is $1.1 \mathrm{~kW}$. The $T_{\text {wall }}$ can be calculated by the following equation, where $L_{\text {in }}$ represents the distance from the first row of holes to the surface of the flow channel,

$$
T_{\text {wall }}=T_{1}-\frac{q^{\prime \prime}}{\lambda} L_{\text {in }}
$$

where $T_{1}$ is the temperature recorded by the thermocouples at the first row. As shown, before the ONB point, the wall temperature will increase with the increase of the heating length. After the ONB point, part of the energy is consumed for bubble growth, resulting in the wall temperature increasing much slower. The accuracy of this method depends on the distance between the thermocouples. For example, the position of the ONB site in Figure 6 is within a $4 \mathrm{~cm}$ interval between No. 9 point and No. 11 point.

Figure 7 shows three photos at a fixed area around No. 10 point with different heating powers, and the size of the observed window is $20 \mathrm{~mm} * 16 \mathrm{~mm}$. It can be seen that when heating power is equal to $1 \mathrm{~kW}$, bubbles begin to appear, and the number of bubbles increases as power increases. So, this point can be considered an ONB point when heating power is equal to $1 \mathrm{~kW}$, but this method is not accurate enough because sometimes the bubble is too small to be observed by the camera. Sometimes, the groove on the wall will cause the bubble to be generated in advance before reaching the ONB condition. Figure 8 shows wall superheat at fixed No. 10 point, increasing heat flux stepwise. Points in the single-phase region and two-phase region are fitted by straight lines. The intersection of two lines is the ONB point [7]. The accuracy of this method is affected by the power step size, which can be modified more efficiently during the experiment. So, in the following text, the third method was adopted to determine the 
TABLE 4: Three identification methods of two channels.

\begin{tabular}{lcc}
\hline & Channel a & Channel b \\
$D_{\text {hy }}(\mathrm{mm})$ & 3.50 & 5.35 \\
Criteria by Kandlikar & Conventional channel & Conventional channel \\
Bd & 0.57 & 4.68 \\
Criteria by Cheng and Wu & Minichannel & Conventional channel \\
Co & 1.32 & 0.46 \\
Criteria by Kew and Cornwell & Microchannel & Conventional channels \\
\hline
\end{tabular}

$1 \mathrm{~ms} \quad 10 \mathrm{~ms} \quad 100 \mathrm{~ms} \quad 180 \mathrm{~ms} \quad 230 \mathrm{~ms}$

$\begin{array}{lllll}1 \mathrm{~mm} \\ 0.5 \mathrm{~ms} \perp 1 \mathrm{~mm}, 1 \mathrm{~ms} & 3 \mathrm{~ms} & \text { (a) } 5 \mathrm{~ms} & 7 \mathrm{~ms} & 10 \mathrm{~ms}\end{array}$

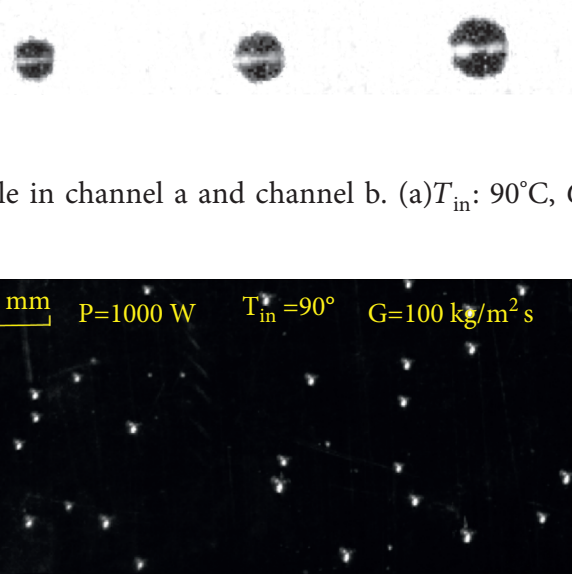

(a)

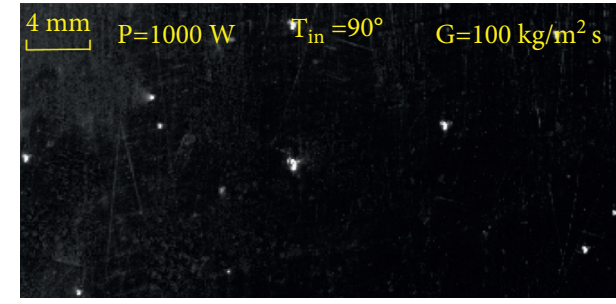

(b)

Figure 5: Bubble nucleation sites in channel a and channel b. (a) $T_{\text {in }}: 90^{\circ} \mathrm{C}, G: 100 \mathrm{~kg} /\left(\mathrm{m}^{2} \cdot \mathrm{s}\right), \mathrm{P}: 1000 \mathrm{~W} .(\mathrm{b}) T_{\mathrm{in}}: 90^{\circ} \mathrm{C}, \mathrm{G}: 100 \mathrm{~kg} /\left(\mathrm{m}^{2} \cdot \mathrm{s}\right), \mathrm{p}:$ $1000 \mathrm{~W}$.

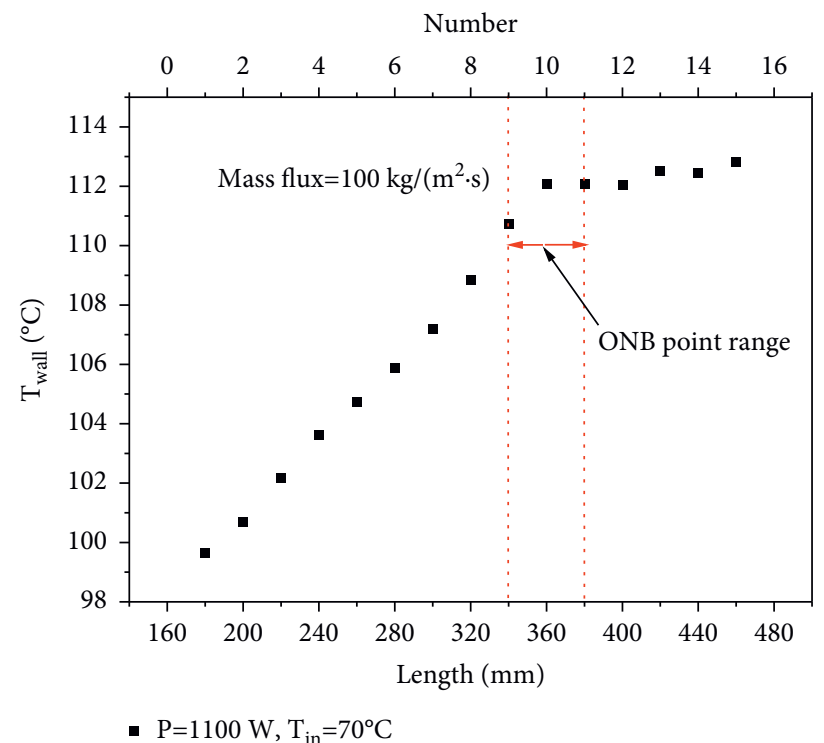

Figure 6: Axial wall temperature distribution in channel b $\left(T_{\text {in }}: 70^{\circ} \mathrm{C}, G: 100 \mathrm{~kg} /\left(\mathrm{m}^{2} \cdot \mathrm{s}\right)\right)$. 

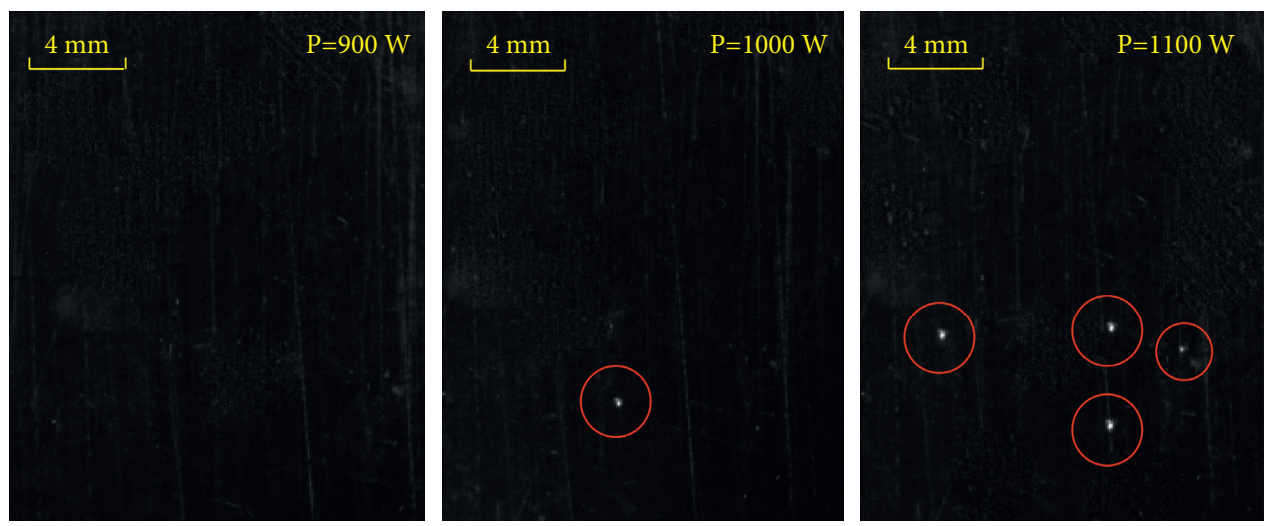

Figure 7: Photos of ONB site in channel b $\left(T_{\text {in }}: 70^{\circ} \mathrm{C}, G: 100 \mathrm{~kg} /\left(\mathrm{m}^{2} \cdot \mathrm{s}\right)\right)$.

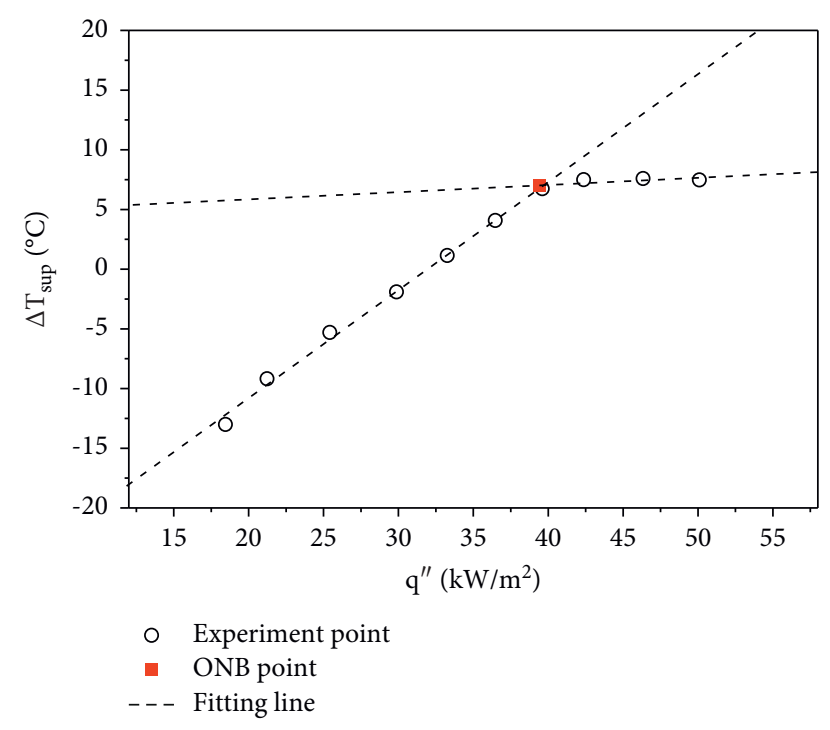

Figure 8: Wall superheat at a fixed point in channel b $\left(T_{\text {in }}: 70^{\circ} \mathrm{C}, G\right.$ : $\left.100 \mathrm{~kg} /\left(\mathrm{m}^{2} \cdot \mathrm{s}\right)\right)$.

position of ONB points. The first two methods are used to verify the calculated position is reasonable.

3.3. Influence of Subcooling and Mass Flux. The effects of inlet temperature and mass flux on $\Delta T_{\text {sup }}$ (the wall superheat) have been studied. Figure 9 shows the change trends of $\Delta T_{\text {sup }}$ with different inlet fluid temperatures when mass flux keeps at $100 \mathrm{~kg} / \mathrm{m}^{2} \mathrm{~s}$ in channel a. The solid points represent ONB sites calculated by the method mentioned in the previous section, and the superheat degree $\Delta T_{\text {sup }}$ at ONB site is $\Delta T_{\mathrm{ONB}}$. Then, by this way, all the ONB sites from many experiments with the same conditions $\left(G=100 \mathrm{~kg} /\left(\mathrm{m}^{2} \cdot \mathrm{s}\right)\right)$ are shown in Figures 10 and 11. It can be observed that $\Delta T_{\mathrm{ONB}}$ has an increasing trend with the decrease of inlet temperature in two channels. Since the bubbles in channel a are difficult to move after nucleation, the bubbles in channel b will lift off, leading to a disturbance of the thermal boundary layer. Hence, the heat flux in channel a is uniform and stable under the same conditions, but the heat flux in channel $b$ is more widely distributed.

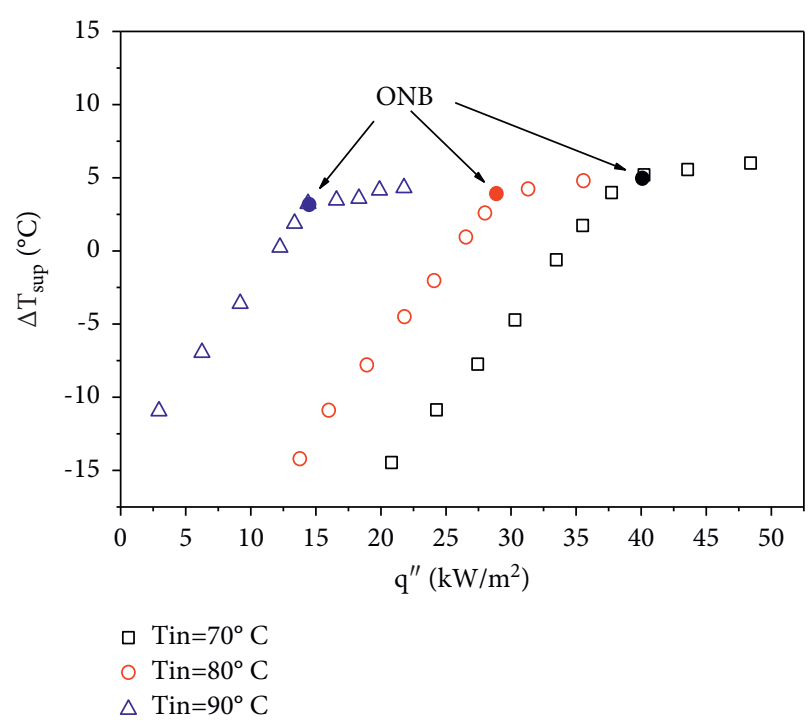

FIgURE 9: Wall superheat at ONB in the channel a $(G: 100 \mathrm{~kg} /$ $\left.\left(\mathrm{m}^{2} \cdot \mathrm{s}\right)\right)$.

Figures 12 and 13 show the effect of mass flux in channel a and channel $\mathrm{b}$ when $T_{\text {in }}$ keeps at $90^{\circ} \mathrm{C}$. It can be found that $\Delta T_{\text {ONB }}$ increases as mass flux increases in both channels. The relationships of $\Delta T_{\mathrm{ONB}}$ with mass flux and inlet temperature are consistent with the conclusions in the works of literature $[8,9]$.

3.4. Comparison with Correlations. The experimental data (100 points) have been compared with theoretical values calculated by equations in Table 1, as shown in Figure 14. It can be seen that Hsu's, Bergles's, Sato's, and Kandlikar's correlations underestimate wall superheat. This may account to that they are all based on a nucleation model proposed by Hsu [1] where bubbles generated in small caves on the heated surface and linear temperature profile was preassumed in the superheated layer. The presence of air pockets on the heated surface can significantly reduce the wall superheat required to generate bubbles. But Hsu's model makes the generation of bubbles on the wall more accessible and underestimates $\Delta T_{\mathrm{ONB}}$. Values predicted by 


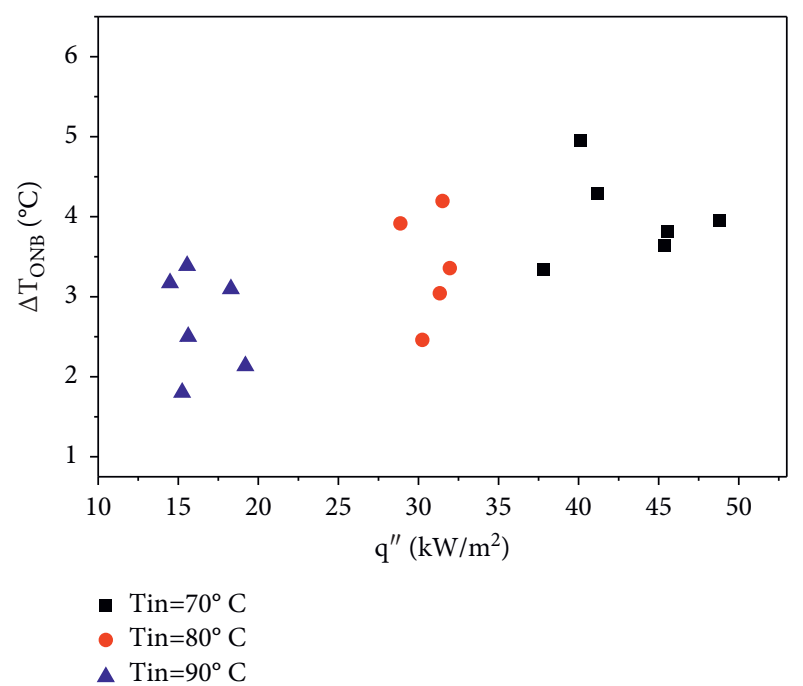

Figure 10: Effect of inlet temperature on $\Delta T_{\text {ONB }}$ in channel a $(G$ : $\left.100 \mathrm{~kg} /\left(\mathrm{m}^{2} \cdot \mathrm{s}\right)\right)$.

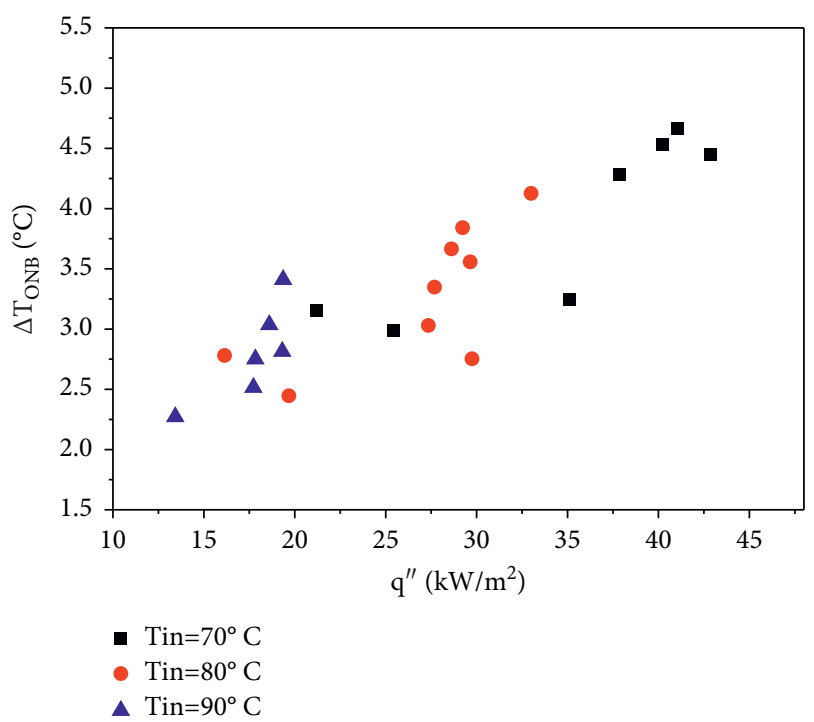

Figure 11: Effect of inlet temperature on $\Delta T_{\mathrm{ONB}}$ in channel b ( $G$ : $\left.100 \mathrm{~kg} /\left(\mathrm{m}^{2} \cdot \mathrm{s}\right)\right)$.

Thom's correlation are closest to the experimental value. Figure 15 shows a comparison between experimental data and indicated values obtained by Thom's correlation. 97\% of the points are in the error range of $\pm 30 \%$, and the mean absolute deviation (MAD) calculated by equation (5) is $27.2 \%$.

$$
\mathrm{MAD}=\frac{1}{N} \sum_{1}^{N} \operatorname{abs}\left[\left(\Delta T_{\text {pre }}-\Delta T_{\exp }\right) / \Delta T_{\exp }\right] .
$$

The existence of differences may be caused by two reasons. (1) The Hsu model assumes that there are gas-filled active cavities of all sizes on the wall, and the actual wall does not necessarily have this property. (2) In Hsu's model, as long as the first bubble is generated on the wall, it is considered the ONB point. But for correlations based on

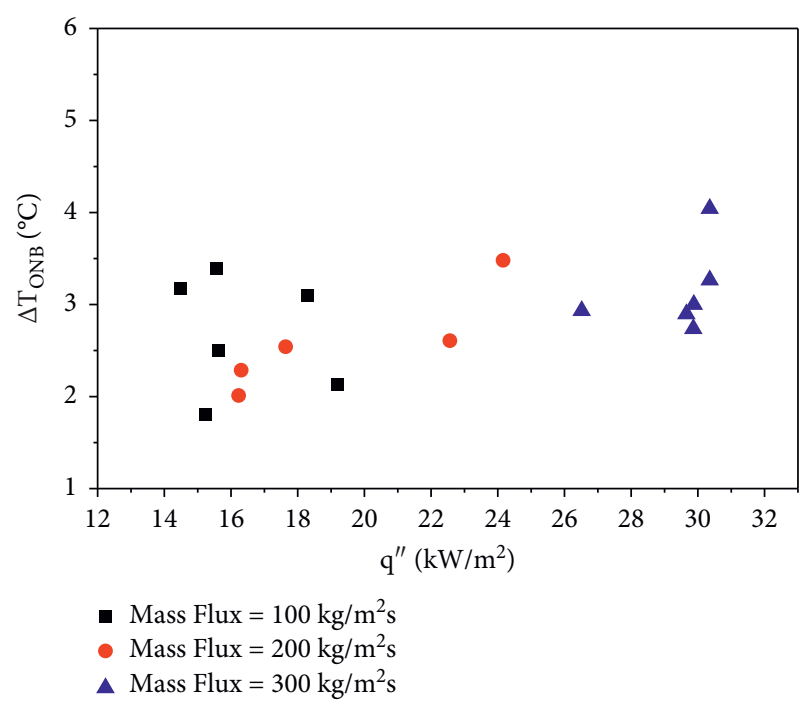

FIgUre 12: Effect of mass flux on $\Delta T_{\mathrm{ONB}}$ in channel a $\left(T_{\mathrm{in}}: 90^{\circ} \mathrm{C}\right)$.

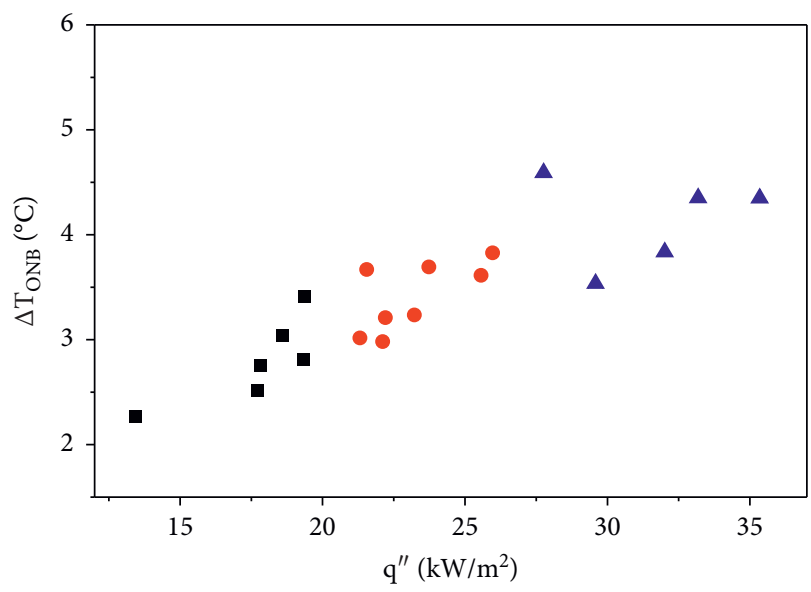

- Mass Flux $=100 \mathrm{~kg} / \mathrm{m}^{2} \mathrm{~s}$

- Mass Flux $=200 \mathrm{~kg} / \mathrm{m}^{2} \mathrm{~s}$

\ Mass Flux $=300 \mathrm{~kg} / \mathrm{m}^{2} \mathrm{~s}$

Figure 13: Effect of mass flux on $\Delta T_{\mathrm{ONB}}$ in channel b $\left(T_{\text {in }}: 90^{\circ} \mathrm{C}\right)$.

experimental data, the point at which heat transfer is converted from a single relative flow heat transfer to a nucleate boiling heat transfer is considered the ONB point. Bubbles may have already been produced, but nucleate boiling heat transfer is not dominant.

Figure 16 shows the comparison of the average equivalent radius between two channels over time. High-speed cameras captured five typical bubbles in each flow channel a and $b$, and their equivalent radius was plotted and numbered from 1 to 5. Hollow and solid points of the same colour represent the average equivalent radius of bubbles in channel $\mathrm{a}$ and channel $\mathrm{b}$ under similar heating and flow conditions, respectively. It can be found that the size of the bubble in channel $b$ is significantly larger under similar heating and flow conditions. But, it can also be observed from Figures 14 and 15 that there are no evident differences between $\Delta T_{\mathrm{ONB}}$ got by the $1.8 \mathrm{~mm}$ gap channel and $2.8 \mathrm{~mm}$ gap channel, 


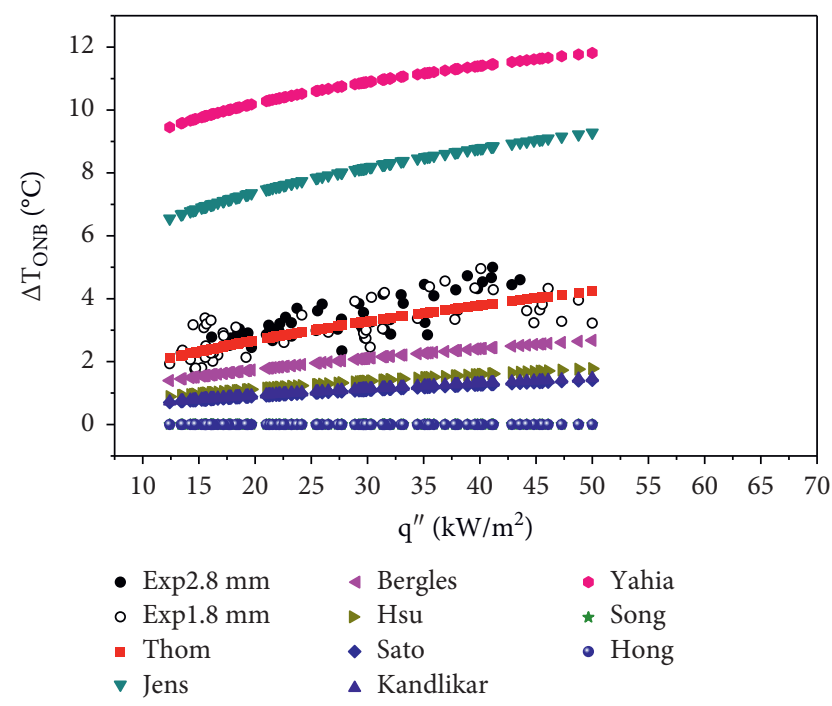

Figure 14: Comparison between experimental data and predicted values.

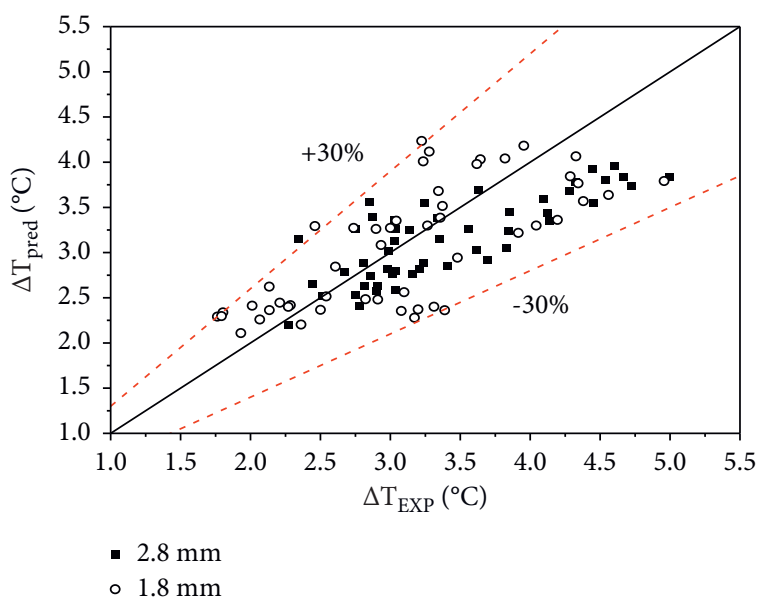

Figure 15: Comparison between experimental data and predicted values got by Thom's correlation.

which means bubbles cause slight differences in heat transfer at ONB site despite the bubble size and bubble shape being different in two channels.

This phenomenon may account for two reasons. (1) Bubbles can be generated near the ONB point. Still, the bubble cannot lift off from the heating wall, and the number of bubbles is small, so the influence of bubbles is relatively small, and the single relative flow heat transfer still dominates. (2)Near the ONB point, although the bubble size is smaller and the detachment frequency is lower in the channel a (Figure 4), the number of nucleation points is more considerable (Figure 5). So, the total amount of evaporation per unit time at the ONB site in two channels is similar. This conclusion is different from Su's experiment [17], where wall superheats at the ONB site are negatively correlated with channel height. It is also different from

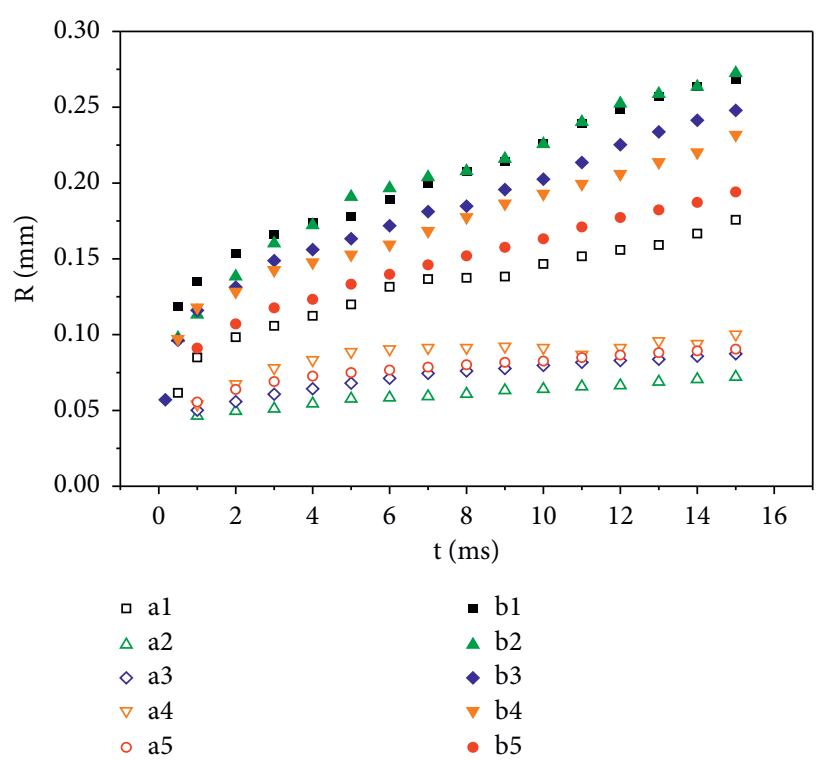

FIGURE 16: Comparison of average equivalent radius between two channels over time $\left(T_{\text {in }}: 90^{\circ} \mathrm{C}, G: 100 \mathrm{~kg} /\left(\mathrm{m}^{2} \cdot \mathrm{s}\right), q^{\prime \prime}: 15 \mathrm{~kW} / \mathrm{m}^{2}\right)$.

TABLE 5: Relative errors.

\begin{tabular}{lcc} 
Heating power $(\mathrm{W})$ & 296.1 & 401.5 \\
Inlet temperature $\left({ }^{\circ} \mathrm{C}\right)$ & 89.8 & 90.4 \\
Mass flow rate $\left(\mathrm{m}^{2} / \mathrm{s}\right)$ & 104.0 & 100.0 \\
Temperature deviation $\left({ }^{\circ} \mathrm{C}\right)$ & 6 & 8 \\
Maximum relative error of heat flux & $9.5 \%$ & $7.1 \%$ \\
Wall temperature $\left({ }^{\circ} \mathrm{C}\right)$ & 110 & 110 \\
Heat flux $\left(\mathrm{W} / \mathrm{m}^{2}\right)$ & 69000 & 69000 \\
$\begin{array}{l}\text { Distance between thermocouples and wall } \\
\text { (mm) }\end{array}$ & 4.0 & 3.0 \\
Maximum relative error of $\Delta T_{\mathrm{ONB}}$ & $1.56 \%$ & $0.98 \%$ \\
\hline
\end{tabular}

correlations by Song et al. and Hong et al. in Table 1. where the channel size can positively affect wall superheat by Re.

\section{Conclusions}

The onset of nucleate boiling in a narrow rectangular channel and a nonnarrow rectangular channel has been visually investigated, and some conclusions can be drawn:

(1). In two channels, $\Delta T_{\mathrm{ONB}}$ has an increasing trend with the decrease of inlet temperature, and it increases as mass flux increases.

(2) Thom's correlation performs the best for predicting $\Delta T_{\mathrm{ONB}}$ in a vertical rectangular channel with $97 \%$ of the points in the error range of $\pm 30 \%$, and the mean absolute deviation is $27.2 \%$. While correlations developed from Hsu's model will underestimate wall superheat.

(3) $\Delta T_{\text {ONB }}$ got by the $1.8 \mathrm{~mm}$ gap channel and $2.8 \mathrm{~mm}$ gap channel has no evident differences. Although the channel height can affect bubble size and shape, it has a little effect on ONB field heat transfer. 


\section{Nomenclature}

Symbols

Bd: $\quad$ Bond number

Bo: Boiling number, defined in Table 1

Co: Confinement number

$D_{\text {hy: }}$ Hydraulic diameter of channels $(\mathrm{m})$

$g$ : $\quad$ Gravitational acceleration $\left(\mathrm{m} / \mathrm{s}^{2}\right)$

$G$ : $\quad$ Mass flux $\left(\mathrm{kg} /\left(\mathrm{m}^{2} \cdot \mathrm{s}\right)\right)$

$h_{l v}: \quad$ Latent heat $(\mathrm{J} / \mathrm{kg})$

$k$ : $\quad$ Fluid thermal conductivity $(\mathrm{W} /(\mathrm{m} \cdot \mathrm{K}))$

$L: \quad$ Distance between two rows of holes (m)

$L_{\text {in }}$ : Distance from the first row of holes to the flow channel (m)

$\dot{m}$ : $\quad$ Mass flow rate $(\mathrm{kg} / \mathrm{s})$

MAD: Mean absolute deviation

p: $\quad$ Pressure $\left(\mathrm{N} / \mathrm{m}^{2}\right)$

$P$ : $\quad$ Heating power $(\mathrm{W})$

$q^{\prime \prime}: \quad$ Heat flux $\left(\mathrm{W} / \mathrm{m}^{2}\right)$

Re: Reynolds number

T: $\quad$ Temperature (K)

$u$ : $\quad$ Flow velocity $(\mathrm{m} / \mathrm{s})$

Greek symbols

$\Delta T$ : Temperature deviation (K)

$\lambda$ : Thermal conductivity of stainless steel $(\mathrm{W} /(\mathrm{m} \cdot \mathrm{K}))$

$\rho: \quad$ Density $\left(\mathrm{kg} / \mathrm{m}^{3}\right)$

$\sigma: \quad$ Surface tension $(\mathrm{N} / \mathrm{m})$

\section{Subscripts}

exp: Experiment

in: Inlet

l: $\quad$ Liquid

ONB: Onset of nucleate boiling

pre: Prediction

sat: Saturation

sub: Subcooling

sup: Superheat

v: Vapor.

\section{Appendix}

According to the error transfer formula,

$$
\phi(y)=\sqrt{\left(\frac{\partial f}{\partial x_{1}}\right)^{2} \phi_{x 1}^{2}+\left(\frac{\partial f}{\partial x_{2}}\right)^{2} \phi_{x 2}^{2}+\cdots+\left(\frac{\partial f}{\partial x_{n}}\right)^{2} \phi_{x n}^{2}}
$$

the relative error of heat flux in equation (4) is

$$
\frac{\phi_{q^{\prime \prime}}}{q^{\prime \prime}}=\sqrt{\left(\frac{\phi_{\left(T_{1}-T_{2}\right)}}{T_{1}-T_{2}}\right)^{2}+\left(\frac{\phi_{\Delta L}}{\Delta L}\right)^{2}},
$$

and the relative error of wall temperature is

$$
\frac{\phi_{T_{\text {wall }}}}{T_{\text {wall }}}=\sqrt{\phi_{T_{2}}^{2}+\frac{1}{k_{w}} \frac{\left(\phi_{q^{\prime \prime}}^{2} L_{\text {in }}^{2}+\phi_{L_{\text {in }}}^{2} q^{\prime \prime}\right)}{\left(T_{2}-q^{\prime \prime} L_{\text {in }} / k_{w}\right)}} .
$$

Measurement error given in Table 3 and the most conservative experiment data are used for equations (A.2) and (A.3) to calculate the maximum relative error, which is given in Table 5 .

\section{Data Availability}

The data used to support the findings of this study are available from the corresponding author upon request.

\section{Conflicts of Interest}

The authors declare that they have no conflicts of interest.

\section{Acknowledgments}

This study was supported by the National Natural Science Foundation of China (11305169) and National Key R\&D Program of China (2017YFE 0300604).

\section{References}

[1] Y. Y. Hsu, "On the size range of active nucleation sites on a heating surface," Journal of Heat Transfer, vol. 84, no. 3, pp. 207-213, 1962.

[2] T. Sato and H. Matsumura, "On the conditions of incipient subcooled-boiling with forced convection," Bulletin of JSME, vol. 7, no. 26, pp. 392-398, 1964.

[3] A. E. Bergles and W. M. Rohsenow, "The determination of forced-convection surface-boiling heat transfer," Journal of Heat Transfer, vol. 86, no. 3, p. 372, 1964.

[4] S. G. Kandlikar, "Nucleation characteristics and stability considerations during flow boiling in microchannels," Experimental Thermal and Fluid Science, vol. 30, no. 5, pp. 441-447, 2006.

[5] P. A. Lottes and W. H. Jens, "Argonne national laboratory report," Argonne National Laboratory, Lemont, IL, USA, ANL-4627, 1951

[6] J. R. S. Thorn, W. M. Walker, T. A. Fallon, and G. F. S. Reising, "Conference Proceedings -, Various titles labelled Volumes A to $\mathrm{S}$, Boiling in sub-cooled water during flow up heated tubes or annuli," Symposium on Boiling Heat Transfer in Steam Generating Units and Heat Exchangers, vol. 180, no. 3, pp. 226-246, 1965.

[7] O. S. Al-Yahia and D. Jo, "Onset of Nucleate Boiling for subcooled flow through a one-side heated narrow rectangular channel," Annals of Nuclear Energy, vol. 109, pp. 30-40, 2017.

[8] J. H. Song, J. Lee, S. H. Chang, and Y. H. Jeong, "Onset of Nucleate Boiling in narrow, rectangular channel for downward flow under low pressure," Annals of Nuclear Energy, vol. 109, pp. 498-506, 2017.

[9] G. Hong, X. Yan, Y.-H. Yang, S. Liu, and Y.-p. Huang, "Experimental study on onset of nucleate boiling in narrow rectangular channel under static and heaving conditions," Annals of Nuclear Energy, vol. 39, no. 1, pp. 26-34, 2012.

[10] S. G. Kandlikar, "Fundamental issues related to flow boiling in minichannels and microchannels," Experimental Thermal and Fluid Science, vol. 26, no. 2-4, pp. 389-407, 2002.

[11] P. Cheng, H. Y. Wu, Mesoscale, and M. Phase-Change, "Heat transfer," Advances in Heat Transfer, vol. 39, no. 06, pp. 461-563, 2006. 
[12] P. A. Kew and K. Cornwell, "Correlations for the prediction of boiling heat transfer in small-diameter channels," Applied Thermal Engineering, vol. 17, no. 8-10, pp. 705-715, 1997.

[13] L. Yin and L. Jia, "Confined characteristics of bubble during boiling in microchannel," Experimental Thermal and Fluid Science, vol. 74, pp. 247-256, 2016.

[14] L. Yin, L. Jia, and P. Guan, "Bubble confinement and deformation during flow boiling in microchannel," International Communications in Heat and Mass Transfer, vol. 70, pp. 4752,2016

[15] I. Hapke, H. Boye, and J. Schmidt, "Onset of nucleate boiling in minichannels," International Journal of Thermal Sciences, vol. 39, no. 4, pp. 505-513, 2000.

[16] T. Chen, J. F. Klausner, S. V. Garimella, and J. N. Chung, "Subcooled boiling incipience on a highly smooth microheater," International Journal of Heat and Mass Transfer, vol. 49, no. 23-24, pp. 4399-4406, 2006.

[17] S. Su, S. Huang, and X. Wang, "Study of boiling incipience and heat transfer enhancement in forced flow through narrow channels," International Journal of Multiphase Flow, vol. 31, no. 2, pp. 253-260, 2005. 